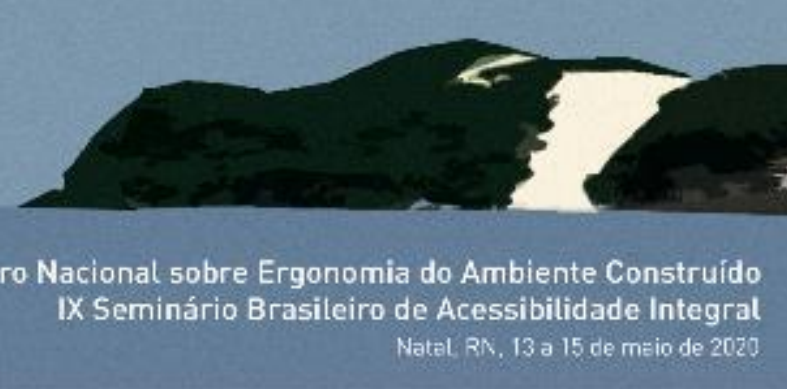

\title{
Acessibilidade em museus para pessoas com deficiência visual: a influência do ambiente construído na experiência de visita
}

\author{
Accessibility in museums for the visually impaired: how the built \\ environment affects the visitor's experience
}

EVELINE ALMEIDA

Mestranda, PUC-Rio, evelinealmeida@gmail.com

CLAUDIA MONT'ALVÃO

Doutora, PUC-Rio, cmontalvao@puc-rio.br

\section{RESUMO}

O espaço expositivo do museu pode tanto se apresentar de forma acolhedora, representando uma possibilidade para o visitante com deficiência visual de explorar seus sentidos e experienciar a exposição de uma maneira própria, como também pode se tornar um espaço excludente, apresentando uma série de barreiras e obstáculos que o impedem de usufruir a exposição. 0 presente trabalho tem como objetivo investigar como os visitantes com deficiência visual interagem com o espaço expositivo do museu, e como o ambiente afeta a experiência da visita. Neste artigo é investigado o estado atual da acessibilidade em museus no Brasil, em particular para as pessoas com deficiência visual, bem como as questões relacionadas ao espaço expositivo e à expografia; a relação entre ambiente museológico e orientação espacial; e como esses fatores afetam a experiência de visita para o público em questão. Pretende-se com este artigo contribuir para o desenvolvimento de futuros estudos e projetos de acessibilidade que ofereçam melhores condições de inclusão social e de democratização do espaço expositivo.

PALAVRAS-CHAVE: museu, deficiência visual, orientação espacial, acessibilidade

\section{ABSTRACT}

The museum's exhibition space can represent a welcoming space, presenting a possibility for the visually impaired visitor to explore all of their senses and experience the exhibition in their particular way. However, it can also represent an excluding space, presenting a series of barriers and obstacles that prevent the visitor from enjoying the exhibition. The research presented in this article aimed to examine how visually impaired visitors interact with the museum's exhibition space and how the environment affects the visitor's experience. The study sought to investigate the current state of accessibility in museums - particularly for people with visual impairments - explore topics like environment and exhibition design, the relationship between museum environment and spatial 


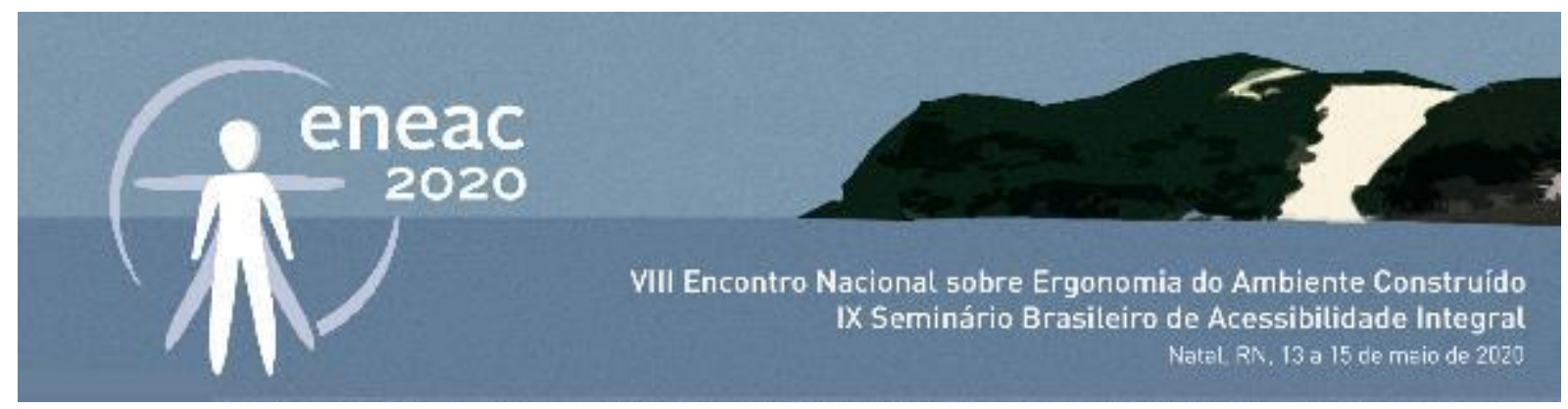

orientation, and how these issues affect the visitor's experience. This article aims to contribute to the development of future studies and projects on accessibility that may represent better opportunities for social inclusion, the democratization of the exhibition space, and the promotion of equitable rights for people with disabilities.

KEYWORDS: museum, visual impairment, spatial orientation, accessibility

\section{INTRODUÇÃO}

Além de sua tradicional função de coleção, preservação e exposição de bens culturais, os museus exercem um importante papel social e educacional na sociedade. Essas instituições se apresentam, conceitualmente, como espaços culturais abertos ao público, a serviço da sociedade e de seu desenvolvimento. Para tanto, é de suma importância que sejam oferecidas condições de amplo acesso e utilização de seus edifícios, suas coleções, seus espaços e demais elementos a todo tipo de visitante (LIMA; BERQUÓ, 2011).

Pensar a acessibilidade de forma universal é promover o acesso livre de barreiras a todas as pessoas. Nas instituições culturais é a garantia do direito a todos de alcançar, perceber, usufruir e participar do que é oferecido com respeito, dignidade e sem barreiras físicas, de comunicação, informação e de atitude. Com isso pode-se dizer que a acessibilidade coloca, para os próprios espaços culturais, questões que dizem respeito à sua missão, função e objetivo enquanto local de promoção e produção de cultura, educação e cidadania.

No entanto, as manifestações, produções e estratégias de mediação cultural permanecem explorando excessivamente a visão, apesar de ser amplamente reconhecido o caráter multissensorial do ser humano. Deixa-se assim de lado toda a riqueza de relações que podem ser estabelecidas de maneira acessível e inclusiva, sem discriminações condicionadas às capacidades dos indivíduos (SARRAF, 2018).

Diante disso, o espaço expositivo pode tanto se apresentar como acolhedor e inclusivo, permitindo assim que o visitante com deficiência visual explore seus outros sentidos e tenha uma experiência própria e singular, como também pode ser um espaço excludente, apresentando uma série de barreiras e obstáculos que o impedem de entender e usufruir a exposição.

O presente artigo é fruto de um estudo mais amplo, parte de uma pesquisa de mestrado em andamento, cujo objetivo é investigar a experiência do visitante com deficiência visual em museus, buscando compreender a relação e a interação entre esse visitante e o ambiente construído do espaço expositivo, bem como seu entendimento das narrativas e do percurso museológico.

Neste artigo são apresentados os resultados da etapa preliminar referente ao levantamento do referencial teórico. Trata-se de um estudo qualitativo de revisão bibliográfica, aplicado com a finalidade de discutir o estado da arte de determinado assunto. Esse estudo é constituído por uma análise da literatura, sem estabelecer uma metodologia rigorosa e replicável em nível de reprodução de dados e respostas quantitativas para questões específicas (VOSGERAU; ROMANOWSK, 2012). Contudo, é de fundamental importância para a aquisição e atualização do conhecimento sobre uma temática específica, evidenciando novas ideias, métodos e subtemas que têm recebido maior ou menor ênfase na literatura selecionada. Procurou-se investigar o estado atual da acessibilidade em 


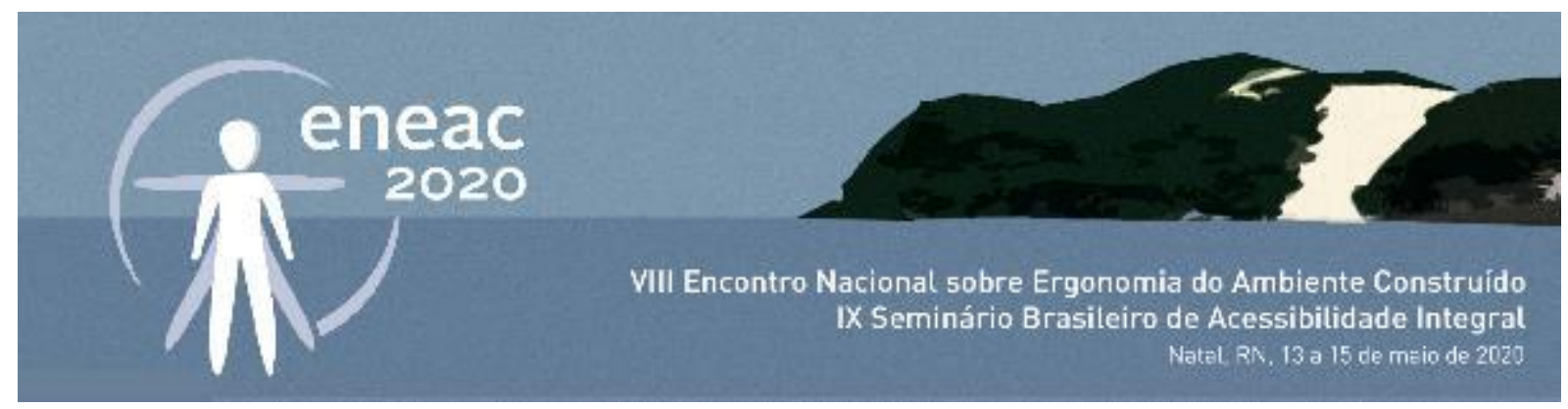

museus no Brasil, em particular para as pessoas com deficiência visual, bem como as questões referentes ao espaço expositivo e à expografia; a relação entre ambiente museológico e orientação espacial; e como esses fatores afetam a experiência de visita para o público em questão.

\section{DEFICIÊNCIA VISUAL E MUSEUS}

O museu é uma instituição dinâmica que, em decorrência das profundas transformações vividas pela sociedade contemporânea, vem sofrendo diversas alterações em suas funções nas últimas décadas. Essas mudanças têm ocasionado um crescimento na popularidade desses espaços culturais, o que reflete não somente em um acréscimo no número de visitantes, mas também na diversidade de seu público. Essas novas demandas têm ocasionado um aumento no número dessas instituições ao redor do mundo. Segundo dados do Instituto Brasileiro de Museus - IBRAM (2011, p.59), "existem, hoje, cinco vezes mais museus no Brasil do que havia na década de 1970 e duas vezes mais que no início da década de 1990".

As definições de museu, enquanto instituição, são resultantes de negociações que têm por finalidade acompanhar os diferentes contextos e realidades de cada época. A definição atual, proposta pelo Conselho Internacional de Museus - ICOMi em 2007, destaca as funções de conservação e exposição dos acervos para fins de educação e pesquisa, e reforça o caráter social do museu ao se propor um espaço aberto ao público, a serviço da sociedade e de seu desenvolvimento. Desse modo, os museus, atuam como espaços para fruição, conhecimento, autoconhecimento e afirmação da identidade sociocultural de seus frequentadores (LIMA; BERQUÓ, 2011).

A inclusão da diversidade de públicos e, por consequência, a promoção da acessibilidade pelas instituições culturais, apresentam-se como novos desafios a serem reconhecidos e trabalhados pelos museus para que estes desenvolvam plenamente sua missão atribuída pelo ICOM para o século XXI: a de serem agentes de transformação social (SARRAF, 2018). Dessa forma, os espaços expositivos podem representar uma excelente oportunidade de se testar e implementar estratégias e projetos de acessibilidade e inclusão que podem, posteriormente, ser replicados em outros espaços.

A Convenção das Nações Unidas sobre os Direitos das Pessoas com Deficiência (CDPD)ii, estabelecida em 2006, e promulgada como decreto no Brasil em 2009, ressalta que a deficiência resulta da interação entre pessoas com deficiência e barreiras comportamentais e ambientais que impedem sua participação plena e eficaz na sociedade de forma igualitária (BRASIL, 2009). Desse modo, a incapacidade não é atribuída à pessoa, evidenciando assim a responsabilidade coletiva no respeito pelos direitos humanos, na construção de uma sociedade mais igualitária e no questionamento de estigmas e preconceitos que podem impedir a promoção da inclusão social (SANTOS, 2011).

De acordo com a Cartilha do Censo 2010 - Pessoas com Deficiência, divulgada em 2012, o Brasil apresentava até então mais de 45 milhões de pessoas com algum tipo de deficiência, o que corresponde a $23,9 \%$ da população total. Dentre as deficiências levantadas, a deficiência visual apresentou a maior ocorrência, afetando $18,6 \%$ da população (SDH-PR; SNPD, 2012).

A visão é o sentido mais explorado nas exposições e este fato contribui para a formação de uma barreira na comunicação entre museus e visitantes (SARRAF, 2008). Na sociedade contemporânea, a presença de estímulos visuais tem sido preponderante no dia a dia das pessoas e encerra um vasto e significativo repositório de informações. O mundo atual é predominantemente um mundo visual, no 


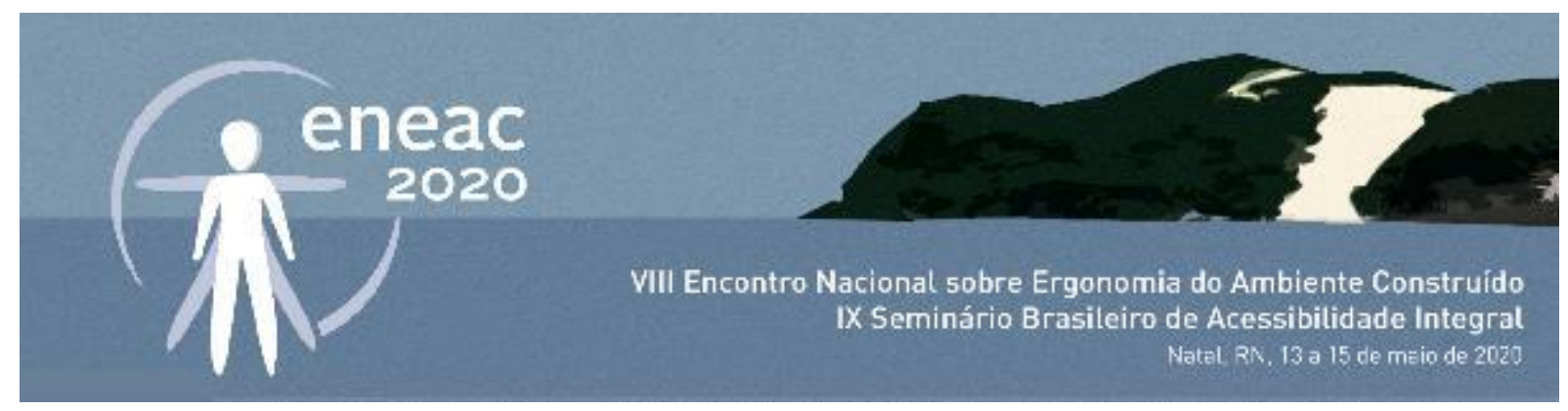

qual as imagens 'falam' a todo o tempo, mas nem sempre se consegue 'traduzir' as mensagens que as imagens carregam (LIMA, BERQUÓ, 2011).

Como produtos dessa sociedade visual, os ambientes museológicos convidam os visitantes a estabelecerem uma relação com o conteúdo exposto através, principalmente, da exploração visual (LIMA; BERQUÓ, 2011). Sarraf (2008, pg.28) destaca que "é possível observar as pessoas visitando as exposições sem se envolverem com o conteúdo apresentado, como se fossem consumidores em frente à vitrine de uma loja. Tudo o que veem parece igual e distante de sua realidade."

O papel das pessoas com deficiência visual no panorama museológico internacional tem sido objeto de reflexões e discussões por parte de artistas, curadores e educadores de museus desde o século XIX, destaca Pereira (2019). De forma geral, a sociedade considera que as pessoas que têm uma deficiência visual não demonstram o mesmo interesse em visitar museus ou outros espaços culturais pelo simples fato de não conseguirem enxergar (PEREIRA, 2019). No entanto, os membros de uma sociedade têm garantidos por lei, o direito de usufruir das mesmas oportunidades e escolhas que todos.

A Lei no 13.146, de 6 de julho de 2015, denominada Lei Brasileira de Inclusão da Pessoa com Deficiência, em seu artigo 10 demonstra seu intuito de "assegurar e promover, em condições de igualdade, o exercício dos direitos e das liberdades fundamentais por pessoa com deficiência, visando à sua inclusão social e cidadania" (BRASIL, 2015). No que tange à acessibilidade, seu artigo 3으, a considera como sendo, dentre outros pontos ${ }^{i i i}$, a possibilidade de utilização, com segurança e autonomia, de espaços, edificações, informação e comunicação, bem como de outros serviços e instalações abertos ao público.

As adequações resultantes de práticas de acessibilidade trazem benefícios não somente às pessoas com deficiência, mas a toda a comunidade. Por exemplo: ao substituir os degraus por rampas em ambientes com desnível, o espaço torna-se acessível não somente a pessoas em cadeiras de rodas, como também facilita a locomoção de pessoas idosas ou com mobilidade reduzida, adultos com carrinhos de bebê, e até o uso de carrinhos de transportes de materiais (SARRAF, 2018).

As instituições e as entidades culturais têm demonstrado um crescente interesse em incluir as pessoas com deficiência visual em espaços museológicos. No entanto, ressalta Pereira (2019), são vários os obstáculos que obstruem a possibilidade de participação na vida cultural de forma autônoma. As instituições têm refletido sobre a questão da acessibilidade em museus, porém, de forma limitada. O foco continua sendo o acesso físico, em especial para quem apresenta algum tipo de deficiência motora, deixando de lado as demais necessidades (PEREIRA, 2019).

\section{ESPAÇO EXPOSITIVO - A CONSTRUÇÃO DA EXPERIÊNCIA MUSEAL}

Assim como as edificações que os abrigam, os espaços onde ocorrem as exposições também foram sendo alterados ao longo do tempo, sob a influência de diversos movimentos políticos, sociais e culturais. Há hoje uma grande variedade de tipologias de museus, bem como de estilos arquitetônicos e expositivos. Embora possa apresentar aspectos variados, é no espaço expositivo que ocorre a experiência museal entre patrimônio e sociedade (SABINO; GUIMARÃES, 2017).

A experiência do visitante no interior da sala de exposição de um museu está relacionada à percepção do individuo com relação a esse ambiente e está conectada com outras, vividas por ele 


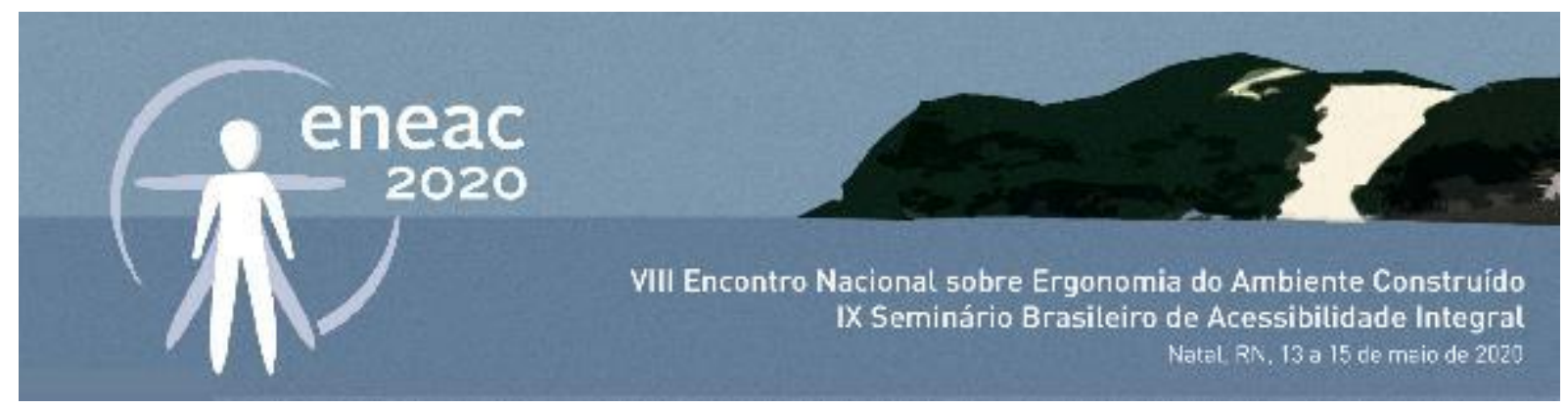

anteriormente, podendo assim também influenciar vivências posteriores à visita. Segundo Cury (2005a), a experiência pode ser entendida como resultado de um processo de interpretação e de comunicação ocorrida no espaço, podendo se apresentar em diferentes níveis: entre indivíduo e objeto, entre indivíduo e ambiente construído, entre indivíduo e espaço vivenciado e entre os diferentes indivíduos presentes no espaço.

A percepção ambiental que os visitantes terão de uma exposição é definida, dentre outros fatores, pela organização interna do espaço expositivo (COSTA, 2014). A arquitetura afeta o modo como se vivencia o museu, pois por meio dela é possível projetar a exploração do espaço de acordo com a relação entre as salas, as galerias e os demais ambientes (TZORTZI, 2011).

A forma como o visitante navega pelos espaços é o que determina o que vai ser experienciado e apreendido. Bitgood (2013) ressalta a necessidade de se projetar sistemas de navegação do espaço que sejam eficientes para a captura da atenção do visitante, de modo que sua locomoção neste espaço gere o mínimo de esforço e frustração, e que o mantenha engajado com a exposição. Logo, se o ambiente se apresentar de forma confusa, não fornecendo pistas claras do caminho a ser seguido, isso pode ocasionar uma diminuição do nível de engajamento e de atenção do visitante, o que pode gerar desinteresse e fadiga (MEDEIROS, 2017).

O percurso expositivo é resultado de um projeto interdisciplinar que determina o direcionamento a ser seguido, definindo assim as possibilidades de interação. Hughes (2010) descreve a organização interna do espaço da exposição como possuindo dois níveis. O primeiro nível é definido pela arquitetura que, em edificações históricas ou adaptadas, está limitada pelas características arquitetônicas do edifício, onde o percurso é projetado utilizando-se de salas interligadas. Já em edifícios projetados especificamente para abrigar museus, o projeto já prevê um espaço amplo, permitindo maior criatividade na construção do circuito expositivo. O segundo nível corresponde à forma como o conteúdo está organizado, onde o intuito é criar uma unidade entre os itens do conjunto exposto, a fim de que a organização dos ambientes possibilite a criação de uma história coesa e passível de ser entendida pelo visitante.

Figueiredo-Lanz (2016) descreve o circuito expositivo como sendo formado por diversos signos que podem contribuir para que o visitante desenhe um mapa mental da exposição. O percurso pode oferecer ao visitante elementos para que ele possa construir uma história e assim obter novos conhecimentos. Essa obtenção representaria a união do universo já existente no visitante - anterior à entrada no museu - e o repertório apreendido durante a exposição. Ou seja, a construção de um repertório novo, de novos valores e conhecimentos (FIGUEIREDO-LANZ, 2016).

A sequência proposta pelo circuito expositivo, em um primeiro momento, pode despertar o interesse do visitante e, em um segundo momento, dar a ele tempo para que reflita sobre as informações apreendidas anteriormente. Na sequência, mais dados podem ser fornecidos para que o visitante faça novas conexões. Dessa forma, o projeto do circuito pode manter uma certa dinâmica fazendo com que o público seja estimulado a buscar mais informações a cada sala, mas que ainda assim proporcione momentos de reflexão durante o percurso (FIGUEIREDO-LANZ, 2016).

$\mathrm{O}$ ato de ocupação do espaço e do tempo de visita, e a forma como o visitante interage com os recursos expográficos - textos, legendas, mobiliário, cenografia, recursos audiovisuais - são fundamentais para a construção da experiência museal. O visitante apropria-se do espaço, criando assim uma trajetória própria, mesmo que o percurso seja predefinido. Apropria-se também do 


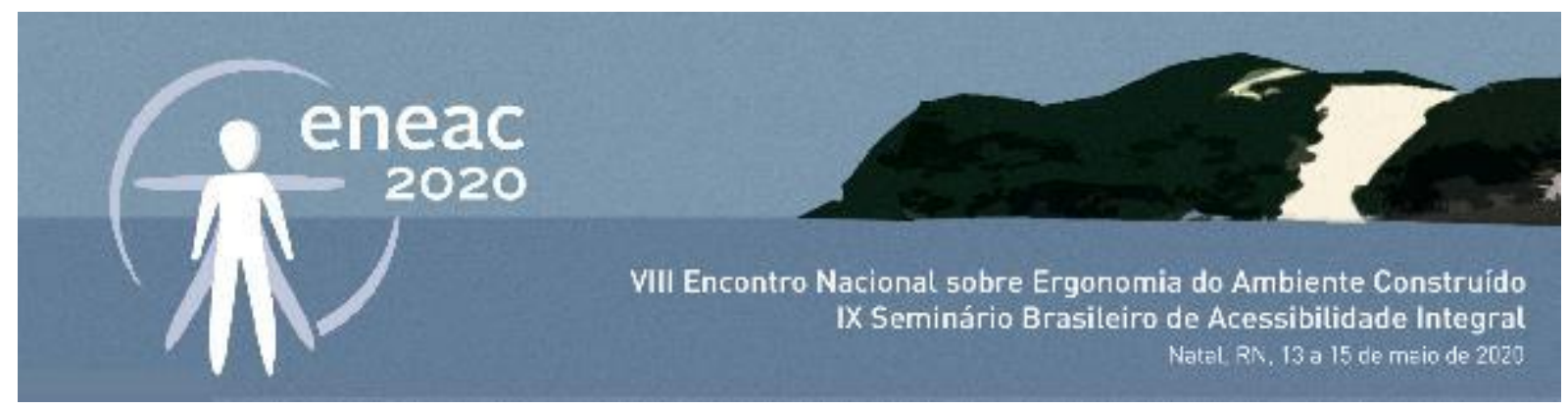

tempo, que se manifesta em seu próprio ritmo. Nessa apropriação de tempo e espaço, o corpo é o ponto de partida para a percepção sensorial do ambiente (CURY, 2005b). Dessa forma, a compreensão e o entendimento que o indivíduo terá do conteúdo exposto estão relacionados ao funcionamento do seu próprio corpo por meio do movimento e da percepção sensorial (SABINO; GUIMARÃES, 2017).

\title{
4 O PERCURSO EXPOSITIVO E A ORIENTAÇÃO ESPACIAL DA PESSOA COM DEFICIÊNCIA VISUAL
}

O espaço expositivo é, por natureza, um espaço mediado. "Sempre haverá uma intencionalidade na exposição do objeto, visto que o objeto não fala por si mesmo, mas é interpretado e reinterpretado por diversas vozes" (SABINO; GUIMARÃES, 2017, pg.15). O processo de experiência do visitante com a exposição está intimamente ligado à sua vivência sensorial, pois "nosso entendimento de mundo se dá a partir da relação que estabelecemos com ele a partir de nosso corpo" (SABINO; GUIMARÃES, 2017, pg.15).

A prática projetual do ambiente construído ainda se encontra muito focada no sentido da visão, o que dificulta o processo de elaboração de uma rota mental adequada para as pessoas com deficiência visual, "a qual lhes permita autonomia e desenvoltura na interação com o ambiente espacial, devido a inexistentes ou insuficientes marcos referenciais em um determinado espaço" (SANTOS; COSTA, 2015, pg.3).

Para Passini (1996) as dificuldades impostas por estruturas físico-espaciais expõem as pessoas a frustrações, estresse e perda de tempo, além de sentimentos de dependência e de incapacidade para realizar atividades de forma autônoma. Sabino e Guimarães (2017), descrevem situações em que o espaço expositivo pode se mostrar desafiador e intimidante para as pessoas com deficiência visual:

\begin{abstract}
Ressalta-se que o espaço intimida ao não permitir a autonomia do visitante e que esta não é efetiva se uma pessoa precisar ser acompanhada em todo percurso por um atendente, ser excluído de visitar determinadas galerias ou ambientes de convivência, de ter acesso a objetos ou documentos fundamentais para compreensão da exposição, não compreender um texto se este for extenso, rebuscado ou com iluminação insuficiente, ter de obedecer um horário determinado para sua visita ou realizar uma agendamento prévio ou ainda se precisar se submeter a entradas pelos fundos ou locais que a coloquem em situações de constrangimento (SABINO; GUIMARÃES, 2017, pg.16).
\end{abstract}

Essas dificuldades podem ser evitadas ou amenizadas, durante a prática projetual, ao se levar em consideração a forma como as pessoas com deficiência visual se orientam no espaço. A orientação espacial, segundo Felippe e Felippe (1997), é definida como sendo a habilidade de um indivíduo de perceber o ambiente, estabelecendo relações corporais, espaciais e temporais com o mesmo.

A orientação espacial não é apenas influenciada pelas vivências sensoriais de cada indivíduo, mas também depende da capacidade do espaço de oferecer as informações necessárias (BINS ELY, 2004). Os projetos de orientação espacial para pessoas com deficiência visual exigem uma análise detalhada do espaço, identificando informações potenciais que permitam a localização e a identificação de atividades, percursos, referenciais, bem como a compreensão das relações espaciais e das narrativas museológicas (BINS ELY; DISCHINGER, 2010).

Segundo Castro et al (2004), a orientação é um dos mais importantes aspectos de autonomia a ser considerado, sobretudo por aqueles que têm restrições visuais. As pessoas com deficiência visual 


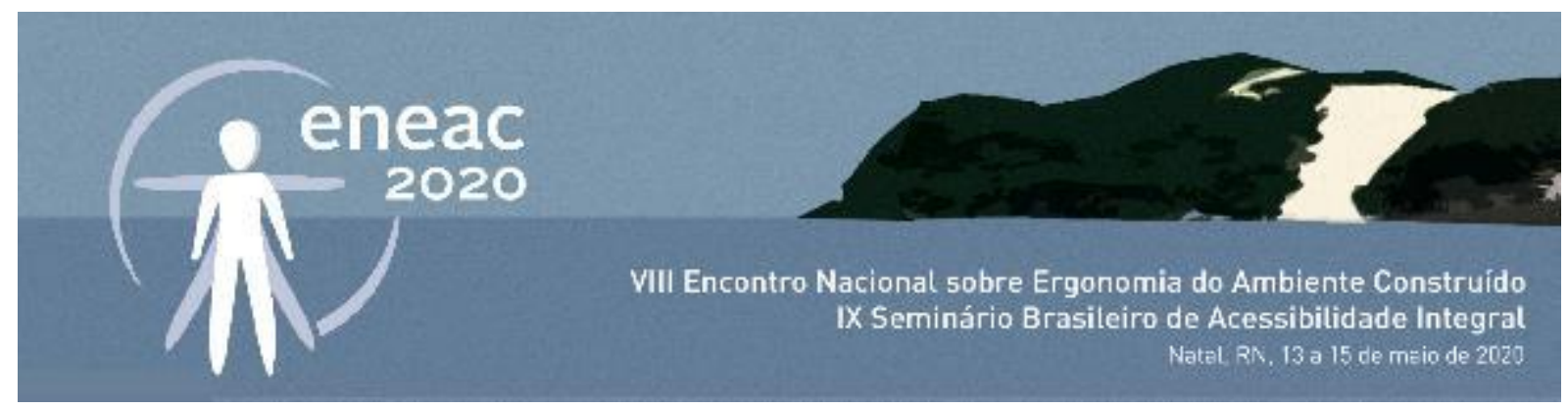

percebem os espaços através de mecanismos e estratégias sensoriais que são diferentes daqueles empregados por pessoas videntes ${ }^{\text {iv }}$ (SANTOS; COSTA, 2015).

A criação de ambientes "visuais" que não levam em consideração o caráter multissensorial do visitante, geram "espaços distorcidos" por não estarem compatíveis com as necessidades de toda a diversidade de pessoas (SANTOS; COSTA, 2015). Froyen (2006 apud BRANDÃO, 2011) destaca o caráter multissensorialv ${ }^{v}$ do visitante que é geralmente ignorado durante a prática projetual:

\footnotetext{
O sentido tátil (texturas ao pisar, paredes, corrimãos, correntes de ar, radiação solar, etc), sons (tráfego, vozes, pássaros, vento, passos, eco, etc.), odores (tráfego, lixo, perfumes, comidas, plantas, etc.), tudo contêm uma rica, mas geralmente ignorada paleta de impulsos para uma experiência sensorial (FROYEN, 2006 apud BRANDÃO, 2011, pg.27).
}

Projetos de espaços expositivos que explorem a multissensoralidade podem se mostrar desafiadores e complexos, porém são de extrema importância para a prática da acessibilidade integral. Faria e Elali (2012) defendem um projeto participativo durante a fase de desenvolvimento, visando estreitar o contato entre projetistas e usuários, pois "no caso da ausência total ou parcial de visão, boas soluções exigem, além de conhecimento teórico, contato direto com usuários" (FARIA; ELALI, 2012, pg.64)

A participação de pessoas com deficiência em propostas de curadorias acessíveis resulta na mudança das linguagens e dos modelos tradicionais de produção, possibilitando o diálogo e o conhecimento de necessidades e anseios desses indivíduos por meio do protagonismo e da criação de novos projetos (SARRAF, 2018).

O convívio e o diálogo com pessoas que apresentam alguma restrição visual são práticas importantes a fim de se compreender essa especificidade perceptiva e mostram-se como um caminho indispensável para solucionar problemas de orientação espacial e, consequentemente, incluir a acessibilidade na prática projetual (SANTOS; COSTA, 2015). Os benefícios resultantes desses projetos não se aplicam apenas às pessoas com deficiência como podem também contribuir para criação de experiências museais mais ricas e engajantes.

\section{CONSIDERAÇÕES FINAIS}

Considerando as informações e análises apresentadas ao longo deste artigo e o atual cenário de transformações e alterações dos museus e seus espaços expositivos, é possível afirmar que há um crescente interesse em se promover práticas e ações culturais acessíveis em todo o país. Há também uma conscientização da sociedade em relação à importância da promoção da inclusão cultural das pessoas com deficiência.

A organização do ambiente museológico e do percurso expositivo afetam a forma como o visitante vivencia o museu. A criação de um espaço seguro e receptivo é de grande importância para o estabelecimento de processos cognitivos que serão responsáveis pela interpretação e apreensão das informações transmitidas pela exposição, e consequentemente influenciarão a experiência da visita.

É importante que os sistemas de navegação do espaço expositivo sejam eficientes para a captura da atenção do visitante, de modo que a locomoção no espaço gere o mínimo de esforço e frustração, visando promover uma experiência de visita eficiente e satisfatória. Projetos de orientação espacial 


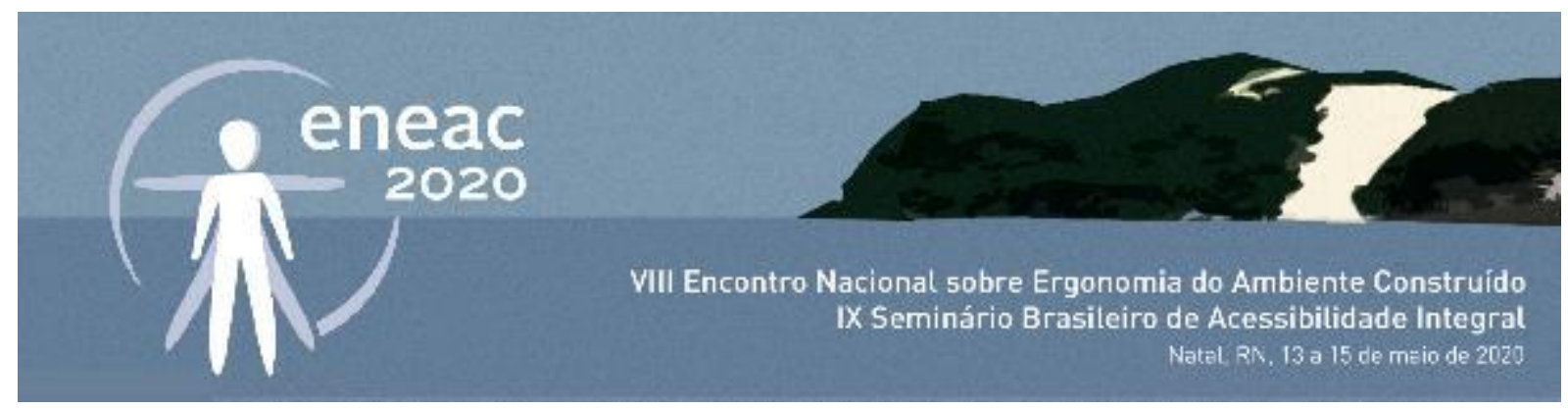

para pessoas com deficiência visual exigem uma análise detalhada do espaço, pois elas percebem os espaços através de mecanismos e estratégias sensoriais que são diferentes daqueles empregados por pessoas videntes.

Os sistemas de navegação projetados para as pessoas com deficiência visual devem ser pensados em conjunto com a criação do projeto expográfico, a fim de que o visitante acompanhe a narrativa da exposição e entenda a sequência lógica do percurso expositivo, da mesma forma que os demais visitantes.

O convívio e o diálogo com pessoas com deficiência visual são essenciais para que se possa compreender as especificidades perceptivas, dada a enorme diversidade de graus, níveis e restrições visuais, bem como vivências pessoais e processos cognitivos singulares. Projetos participativos são de fundamental importância para que se possa promover a acessibilidade de forma integral.

Este projeto de pesquisa pretende ser um ponto inicial para uma discussão que envolve várias áreas e profissionais que atuam na concepção do espaço expositivo, como arquitetos, designers, curadores, pesquisadores e educadores. Pretende-se com este artigo contribuir para o desenvolvimento de futuros estudos e projetos de acessibilidade que ofereçam melhores condições de inclusão social e de democratização do espaço expositivo.

\section{AGRADECIMENTOS}

O presente trabalho foi realizado com apoio da Coordenação de Aperfeiçoamento de Pessoal de Nível Superior - Brasil (CAPES) - Código de Financiamento 001

\section{REFERÊNCIAS}

BINS ELY, Vera Helena Moro. Orientar-se no espaço: condição indispensável para a acessibilidade. In: Seminário Nacional de Acessibilidade no Cotidiano, 1., 2004, Rio de Janeiro.

BINS ELY, V. H. M.; DISCHINGER, M. Deficiência visual, processos de percepção e orientação. In: ALMEIDA PRADO et al (org.). Desenho Universal: caminhos da acessibilidade no Brasil. São Paulo: Annablume, 2010.

BITGOOD, Stephen. Visitor navigation and attention. In: BITGOOD, Stephen. Attention and value: keys to understanding museum visitors. New York: Routledge, 2013, p. 166-175.

BRANDÃO, Milena de Mesquita. Acessibilidade espacial para pessoas com deficiência visual: discussão e contribuições para NBR 9050/2004. 2011. 198f. Dissertação (Mestrado em Arquitetura e Urbanismo) - Universidade Federal de Santa Catarina (UFSC). Florianópolis, 2011.

BRASIL. Decreto $n$ o 6.949, de 25 de agosto de 2009. Promulga a Convenção Internacional sobre os Direitos das Pessoas com Deficiência e seu Protocolo Facultativo, assinados em Nova York, em 30 de março de 2007. Diário Oficial [da] República Federativa do Brasil, Brasília, DF, Presidência da República, 26 ago. 2009. Disponível em: <http://www.planalto.gov.br/ccivil 03/ ato2007-2010/2009/decreto/d6949.htm> Acesso em 15 jan. 2020.

BRASIL. Lei 13.146, de 6 de julho de 2015. Institui a Lei Brasileira de Inclusão da Pessoa com Deficiência - Estatuto da Pessoa com Deficiência. Diário Oficial [da] República Federativa do Brasil, Brasília, DF, Presidência da República, 6 jul. 2015. Disponível em: <http://www.planalto.gov.br/ccivil 03/ ato2015-2018/2015/lei/l13146.htm> Acesso em 15 jan. 2020. 


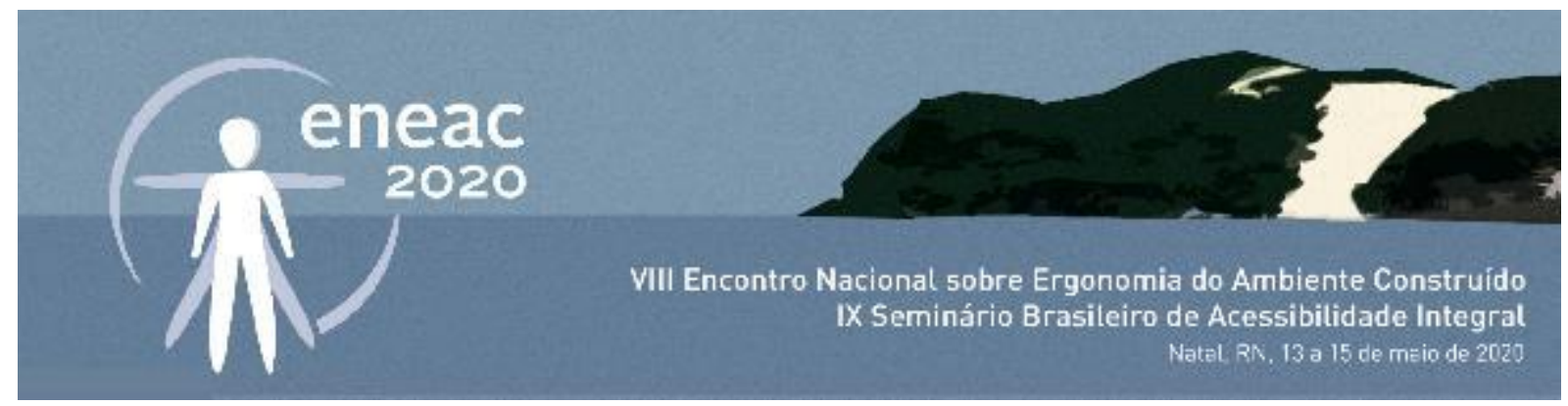

CASTRO, E. M.; PAULA, A. I.; TAVARES, C. P.; MORAES, R. Orientação espacial em adultos com deficiência visual: efeitos de um treinamento de navegação. Psicologia: Reflexão e Crítica, Porto Alegre, v. 17, n. 2, p. 199-210, 2004.

COSTA, Robson Xavier da. Percepção ambiental em museus paisagens de arte contemporânea: a legibilidade dos museus Inhotim/Brasil e em Serralves/Portugal avaliada pelo público/visitante. 2014. 388f. Tese (Doutorado em Arquitetura e Urbanismo) - Centro de Tecnologia, Universidade Federal do Rio Grande do Norte (UFRN). Natal, 2014.

CURY, Marilia Xavier. Exposição: concepção, montagem e avaliação. São Paulo: Annablume, 2005a.

CURY, Marilia Xavier. Comunicação museológica: uma perspectiva teórica e metodológica de recepção. 2005. 366f. Tese (Doutorado em Ciências da Comunicação) - Escola de Comunicações e Artes, Universidade de São Paulo (USP). São Paulo, 2005b.

FARIA, A. T.; ELALI, G. A. Promovendo a inclusão: uma experiência de participação de pessoa com deficiência visual no desenvolvimento de um projeto arquitetônico. Revista Ação Ergonômica, v. 7, n. 2, p. 61-73, 2012.

FELIPPE, J.; FELIPPE, V. Orientação e Mobilidade. São Paulo: Laramara - Associação Brasileira de Assistência ao Deficiente Visual, 1997.

FIGUEIREDO-LANZ, Renata Dias de Gouvêa de. O design de exposições em uma abordagem crítica. In: P\&D - Congresso Brasileiro de Pesquisa e Desenvolvimento em Design, 12., 2016, Belo Horizonte.

HUGHES, Philip. Exhibition Design. London: Laurence King Publishing, 2010.

IBRAM - INSTITUTO BRASILEIRO DE MUSEUS. Museus em números. Brasília: IBRAM, 2011.

ICOM - INTERNATIONAL COUNCIL OF MUSEUMS. Museum Definition. Disponível em: <https://icom.museum/en/activities/standards-guidelines/museum-definition/>. Acesso em 15 jan. 2020.

LIMA, D. F. C.; BERQUÓ, A. F. Informação especial no museu - Acessibilidade: A inclusão social da pessoa com deficiência visual. In: ENANCIB - Encontro Nacional de Pesquisa em Ciência da Informação, 12., 2011, Brasília.

MEDEIROS, Marília Macedo. O Design para a experiência na expografia do museu: A relação entre o ambiente da exposição e a recepção do público no museu Cais do Sertão. 2017, 147f. Dissertação (Mestrado em Design) - Centro de Ciências e Tecnologia, Universidade Federal de Campina Grande (UFCG). Campina Grande, 2017.

PASSINI, Romedi. Wayfinding design: logic, application and some thoughts on universality. Design Studies, Montreal, v. 17, n. 3, p. 319-331, jul. 1996

PEREIRA, Catarina. Representação e práticas de inclusão em espaços museológicos: Pessoas com deficiência visual em museus de arte. 2019, 101f. Dissertação (Mestrado em Estudos Artísticos) - Faculdade de Belas Artes, Universidade do Porto (UP). Porto - Portugal, 2019.

SABINO, P. R.; GUIMARÃES, M. P. A experiência do visitante no espaço expositivo: possibilidades para inclusão social em museus. In: Seminário Brasileiro de Museologia, 3., 2017, Belém.

SANTOS, M. S. S.; COSTA, A. D. L. A orientação físico-espacial de pessoas com deficiência visual: conhecendo o usuário. Revista Nacional de Gerenciamento de Cidades, São Paulo, v. 3, n. 15, p. 193-211, 2015.

SANTOS, Sónia. Museus inclusivos: realidade ou utopia. Ensaios e práticas em museologia, Porto, v. 1, n. 1, p. 306-325, 2011.

SARRAF, Viviane Panelli. Acessibilidade cultural para pessoas com deficiência - benefício para todos. Revista do Centro de Pesquisa e Formação - SESC, São Paulo, n. 6, p. 23-43, jun. 2018.

SARRAF, Viviane Panelli. Reabilitação do museu: Políticas de inclusão cultural por meio da acessibilidade. 2008, 181f. Dissertação (Mestrado em Ciência da Informação) - Escola de Comunicações e Artes, Universidade de São Paulo (USP). São Paulo, 2008. 


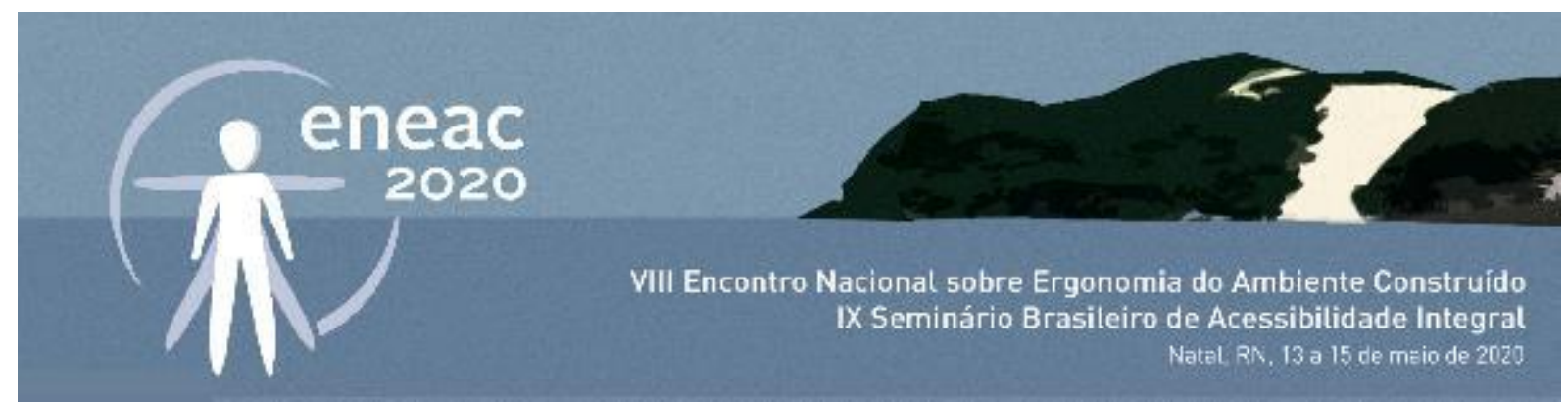

SECRETARIA DE DIREITOS HUMANOS DA PRESIDÊNCIA DA REPÚBLICA (SDH-PR); SECRETARIA NACIONAL DE PROMOÇÃO DOS DIREITOS DA PESSOA COM DEFICIÊNCIA (SNPD). Cartilha do Censo 2010 - Pessoas com Deficiência. Brasília: SDHPR/SNPD, 2012.

TZORTZI, Kali. Designer choices, Museum experiences. In: BALLARIN, M.; MURA, M. D. (org.). Museum and design disciplines. Veneza: Università luav di Venezia, 2011. 33-44 p.

VOSGERAU, D. S. A. R. \& ROMANOWSKI, J. P. Estudos de revisão: implicações conceituais e metodológicas. Revista de Diálogo Educacional, n. 41, p. 165-189, 2014.

\footnotetext{
i “Um museu é uma instituição permanente, sem fins lucrativos, a serviço da sociedade e de seu desenvolvimento, aberta ao público, que adquire, conserva, pesquisa, divulga e expõe, para fins de estudo, educação e lazer, testemunhos materiais e imateriais dos povos e seu ambiente." (ICOM, 2007)

ii "Reconhecendo que a deficiência é um conceito em evolução e que a deficiência resulta da interação entre pessoas com deficiência e as barreiras devidas às atitudes e ao ambiente que impedem a plena e efetiva participação dessas pessoas na sociedade em igualdade de oportunidades com as demais pessoas" (BRASIL, 2009)

iii "I - acessibilidade: possibilidade e condição de alcance para utilização, com segurança e autonomia, de espaços, mobiliários, equipamentos urbanos, edificações, transportes, informação e comunicação, inclusive seus sistemas e tecnologias, bem como de outros serviços e instalações abertos ao público, de uso público ou privados de uso coletivo, tanto na zona urbana como na rural, por pessoa com deficiência ou com mobilidade reduzida;" (BRASIL, 2015)

iv Pessoas que não possuem deficiência visual.

v Que envolve ou implica dois ou mais estímulos sensoriais simultaneamente.
} 